\title{
Bond Strength of Self-etching Adhesives Applied to Different Substrates
}

\author{
${ }^{1}$ Cinthia S Kubo, ${ }^{2}$ Mayra ARV Piccioni, ${ }^{3}$ Mateus R Tonetto, ${ }^{4}$ Matheus C Bandeca, ${ }^{5}$ Milton C Kuga \\ ${ }^{6}$ José RC Saad, ${ }^{7}$ Marcelo F de Andrade, ${ }^{8}$ Edson A de Campos
}

\section{ABSTRACT}

Aim: To evaluate the microshear bond strength and adhesive interface using scanning electron microscopy (SEM) of selfetching adhesive systems on normal and artificially hypermineralized dentin substrates.

Materials and methods: A total of $65(n=65)$ bovine incisors were divided into two groups according to dentin type: Normal $(n=28)$ and artificially hypermineralized $(n=29)$. Composite resin cylinders were placed on these surfaces and cured $\left(3 \mathrm{M}^{\mathrm{TM}} \mathrm{ESPE}^{\mathrm{TM}}\right.$ Filtek $\left.^{\mathrm{TM}} \mathrm{Z350} \mathrm{XT}\right)$. Each group was divided into four subgroups $(n=7)$ according to the self-etching adhesive systems used (Clearfil SE Bond, AdheSE ${ }^{\circledR}$, Adper ${ }^{\mathrm{TM}}$ Easy One, and OptiBond ${ }^{\mathrm{TM}}$ All-In-One ${ }^{\mathrm{TM}}$ ), and microshear bond tests were performed. In addition, one specimen from each group was prepared for an evaluation of the adhesive interface under a microscope ( $\times 2000$ magnification). The differences between the groups were determined using two-way analysis of variance (ANOVA) and Tukey's test $(p<0.05)$.

Results: For normal dentin, the microshear bond strength values in MPa were as follows: Clearfil = 15.65; AdheSE = 14.71; Easy One = 21.92; and OptiBond $=28.43$. For hypermineralized dentin, the values were as follows: Clearfil $=20.96$; AdheSE $=$ 17.23; and OptiBond $=23.29$. There were no significant differences between any of the adhesives used $(p>0.05)$. When adhesion, dentin, and interaction were treated as factors and analyzed, a significant difference was found only in the case of the adhesive $(p=0.0002)$.

Conclusion: Self-etching adhesive systems with higher degrees of acidity do not necessarily exhibit greater microshear bond strength in hypermineralized teeth.

Clinical significance: It is important to obtain bond strength values to analyze the possible clinical performance of the adhesive systems. Furthermore, information on their interactions with different types of dentin substrates proved complementary and useful in the study performed herein.

1,2,6-8 Department of Restorative Dentistry, School of Dentistry Universidade Estadual Paulista, Araraquara, São Paulo, Brazil

${ }^{3,5}$ Department of Dentistry, University of Cuiabá, Cuiabá, Mato Grosso, Brazil

${ }^{4}$ Department of Dentistry, CEUMA University, São Luis, Maranhão Brazil

Corresponding Author: Cinthia S Kubo, Department of Restorative Dentistry, School of Dentistry, Universidade Estadual Paulista, Araraquara, São Paulo, Brazil, Phone: +551633016393, e-mail: cinthiakubo@yahoo.com.br
Keywords: Adhesion, Bond strength, Dental adhesives, Dentin, Scanning electron microscopy.

How to cite this article: Kubo CS, Piccioni MARV, Tonetto MR, Bandeca MC, Kuga MC, Saad JRC, de Andrade MF, de Campos EA. Bond Strength of Self-etching Adhesives Applied to Different Substrates. World J Dent 2017;8(5):358-363.

Source of support: Nil

Conflict of interest: None

\section{INTRODUCTION}

The continued production of ever-more advanced selfetching adhesive systems has resulted in widespread attention from researchers since the efficacy of these systems must be evaluated before they are used in clinical practice. ${ }^{1}$ Both the acidity of the etching system and characteristics of the dentin may affect adhesive bond strength and produce poor interaction between it and the dentin substrate. ${ }^{2}$

The bond strengths of "etch-and-rinse" adhesives and two-step self-etching adhesives have been evaluated in cases of dentinal sclerosis. ${ }^{3-6}$ Studies have concluded that the bond strength of normal dentin is much higher than that of sclerotic dentin. Sclerotic dentin seems to restrict the action of etching acids thus, hindering demineralization and the proper formation of tags. ${ }^{7}$

The literature also includes performance evaluations for adhesives with different compositions and $\mathrm{pHs} .{ }^{8-10}$ However, no studies have investigated the bonding behavior of two-step self-etching adhesives and singlestep self-etching adhesives at different $\mathrm{pHs}^{11}$ in cases of normal and hypermineralized dentin.

Thus, the objective of this study was to evaluate the microshear bond strengths of different self-etching adhesive systems when applied to normal and artificially hypermineralized dentin substrate to determine which associations are most appropriate.

\section{MATERIALS AND METHODS}

A total of 65 bovine teeth free of caries were used in this study. The teeth were cleaned and kept in a $0.1 \%$ thymol solution at $4^{\circ} \mathrm{C}$ until use.

Some of the teeth were selected to have the dentin surface hypermineralized $^{12,13}$ (group H). The vestibular 
surface of each tooth was worn down in an abrasive (DP-10 Panambra, Struers, Ballerup, Denmark) and 320-grit silicon paper polishing was used to expose the facial surface, grind the dentin flat, and standardize the smear layer.

Tooth fragments were cut using a precision cutter (IsoMet 1000, Buehler-An ITW Company). Each crown fragment was placed in a polyvinyl chloride pipe measuring $1.2 \mathrm{~cm}$ in height by $2.0 \mathrm{~cm}$ in diameter with self-curing acrylic resin (classic self-curing acrylic resin, Dencôr, São Paulo, Brazil).

The exposed dentin of each group $\mathrm{H}$ specimen was etched with $32 \%$ phosphoric acid (Uni-Etch Bisco) for 5 second to remove the smear layer. The specimens were then washed for 20 second using distilled water.

Next, the teeth were placed in a mineralized solution containing $1.5 \mathrm{mM}$ calcium (from $\mathrm{CaCl}_{2} 2 \mathrm{H}_{2} \mathrm{O}$ ), $0.9 \mathrm{mM}$ phosphate (from $\mathrm{K}_{2} \mathrm{PO}_{4}$ ), and $0.15 \mathrm{M}$ potassium chloride and were then stored at room temperature. The $\mathrm{pH}$ of the solution $(\mathrm{pH}=7.0)$ was confirmed using a $\mathrm{pH}$ meter (Q400ISE ion meter; Quimis, Brazil). To guarantee stability, the solution was replaced every 23 hours for 14 days and it remained under constant agitation using a magnetic stirrer (KlineNT 151; Novatecnica, Brazil).

After 14 days, the dentin surface was considered hypermineralized. One specimen was selected at random to be molded with adhesion silicon, and a positive replica in epoxy resin was created for observation under SEM to confirm the results of the hypermineralization procedure. ${ }^{14-16}$ The adhesive procedures in group $\mathrm{H}$ were performed 7 days after the teeth were removed from the mineralizing solution; during this 7-day period, the teeth were kept in distilled water.

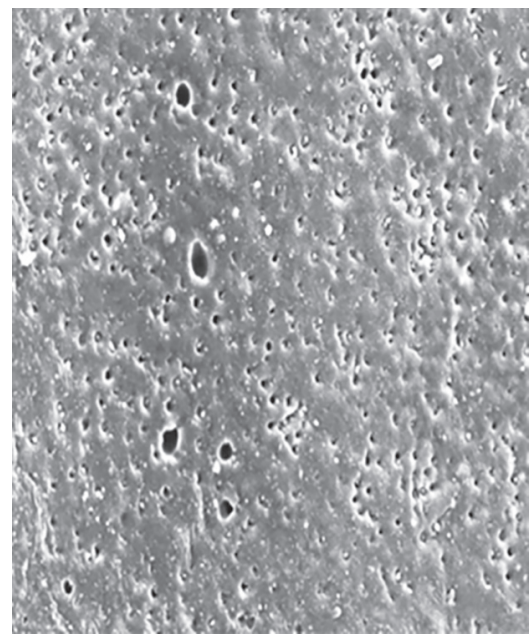

Fig. 1: The SEM providing evidence of artificial dentin hypermineralization

The effect of the mineralizing solution as seen using SEM ( $\times 500$ magnification) is shown in Figure 1. The deposition of crystals into the dentin tubules associated with the increase in peritubular dentin provides evidence of the efficacy of the hypermineralization procedure for simulating sclerotic dentin.

Each group $(\mathrm{n}=28) \mathrm{N}$ and $\mathrm{H}$ was divided into four subgroups $(n=7)$ according to the self-etching adhesive systems used. The adhesives used, their compositions, and the manufacturers' instructions are summarized in Table 1.

To standardize the bonding area, the adhesive area was outlined ${ }^{17}$ with acid-resistant double-sided adhesive tape. The tape was cut into sizes sufficient to cover the surface of the specimen. Each fragment received 4 holes, $0.7 \mathrm{~mm}$ in diameter, using a rubber hole punch to completely isolate

Table 1: Adhesive systems: Characteristic, general composition, manufacturer, manufacturer's instructions

\begin{tabular}{|c|c|c|c|c|}
\hline & Clearfil SE Bond & AdheSE & OptiBond All-In-One & Adper Easy One \\
\hline Characteristic & Two-step-suave & Two-step-moderado & One-step-moderado & One-step-suave \\
\hline \multirow[t]{2}{*}{ Composition } & \multirow[t]{2}{*}{$\begin{array}{l}\text { Primer: MDP, HEMA, water } \\
\text { Adhesive: MDP, HEMA, } \\
\text { bis-GMA, hydrophobic } \\
\text { dimethacrylates, } \\
\text { submicronsilicafillers, } \\
\mathrm{N}, \mathrm{N} \text {-diethanol-p-toluidine, } \\
\mathrm{CQ}\end{array}$} & \multirow[t]{2}{*}{$\begin{array}{l}\text { Primer: } \\
\text { Dimethacrylate, } \\
\text { phosphonic acid } \\
\text { acrylate, water, } \\
\text { stabilizers } \\
\text { Bond: Dimethacrylate, } \\
\text { HEMA, silica, initiators, } \\
\text { and stabilizers }\end{array}$} & \multirow[t]{2}{*}{$\begin{array}{l}\text { Uncured methacrylateester, } \\
\text { ethylalcohol, acetone, } \\
\text { monomers, inertmineralfillers, } \\
\text { ytterbium fluoride, } \\
\text { photoinitiators, accelerators } \\
\text { and stabilizers }\end{array}$} & $\begin{array}{l}\text { Bond: TEG-DMA, } \\
\text { dimethacrylate substitute, } \\
\text { treated silicasilane } \\
\text { dimethacrylate, } \\
\text { methacryloxy-hexilesters, } \\
\text { phosphoric acid, CQ, } \\
\text { 1,6-hexanedioldimethacrylate }\end{array}$ \\
\hline & & & & $\begin{array}{l}\text { Primer: } 10-M D P, H E M A, C Q \text {, } \\
\text { hydrophilic dimethacrylate, } N \text {, } \\
\text { N-diethanol-p-toluidine, water }\end{array}$ \\
\hline Manufacturer & $\begin{array}{l}\text { Kuraray Medical; Tokyo, } \\
\text { Japan }\end{array}$ & $\begin{array}{l}\text { Ivoclar/vivadent; } \\
\text { Schaan, Liechtenstein }\end{array}$ & Kerr; Orange, California, USA & $\begin{array}{l}\text { 3M Espe; St. Paul, } \\
\text { Minnesota, USA }\end{array}$ \\
\hline $\begin{array}{l}\text { Manufacturer's } \\
\text { instructions }\end{array}$ & $\begin{array}{l}\text { Apply primer and leave it } \\
\text { undisturbed for } 20 \text { s; dry } \\
\text { with mild air flow, apply } \\
\text { bond; gently air flow; } \\
\text { photopolymerized for } 10 \mathrm{~s}\end{array}$ & $\begin{array}{l}\text { Apply primer and } \\
\text { agitate for } 20 \mathrm{~s} \text {. Dry } \\
\text { with air stream. Apply } \\
\text { adhesive and dry with } \\
\text { air stream. Light cure } \\
10 \mathrm{~s}\end{array}$ & $\begin{array}{l}\text { Vigorously apply the first } \\
\text { coat } 20 \mathrm{~s} \text {, vigorously apply a } \\
\text { second coat } 20 \mathrm{~s} \text {; dry with air } \\
\text { stream } 5 \mathrm{~s} \text { and light cure } 10 \mathrm{~s}\end{array}$ & $\begin{array}{l}\text { Apply adhesive for } 20 \mathrm{~s} \text {; dry } \\
\text { with mild air flow } 5 \mathrm{~s} \text {; light } \\
\text { cure } 10 \mathrm{~s}\end{array}$ \\
\hline
\end{tabular}

MDP: 10-methacryloxydecyl dihydrogen phosphate; HEMA: 2-hydroxyethyl methacrylate; Bis-GMA: Bisphenol A diglycidyl methacrylate; GPDM: Dimetacrilato de glicerolfosfato; $C Q$ : Canforoquinona 
each tooth. The adhesive side of the tape was stuck to the tooth to outline the four dentin surfaces on which the adhesive systems were applied.

On the other side of the tape, a tripartite matrix was positioned to create composite resin cylinders to allow for all four cylinders to be light-cured at the same time. Transparent R-3603 Tygon tubing (Saint-Gobain Performance Plastics, Clearwater, Florida, USA) was cut using a No. 15 scalpel blade and a cutting device. The tubes were filled with composite resin (3M ${ }^{\mathrm{TM}}$ ESPE ${ }^{\mathrm{TM}}$ Filtek $^{\mathrm{TM}}$ Z350 XT Universal Restorative, shade A3B) and were positioned above the tripartite matrix so that the internal diameter coincided with the hole in the tape. The tubes were photoactivated for 20 second using a curing light (Bluephase, Ivoclar Vivadent, Schaan, Liechtenstein, Germany) at an intensity of $1200 \mathrm{~mW} / \mathrm{cm}^{2}$.

The tubes were cut and removed using scalpel blades to expose the small composite resin cylinders $(0.7 \mathrm{~mm}$ in diameter and $1 \mathrm{~mm}$ in height) with the $0.38-\mathrm{mm}^{2}$ bonding area, both of which were bound to the dentin surface.

After the specimens were stored in a humid environment at $37^{\circ} \mathrm{C}$ for 24 hours, they were adapted to a microshear bond strength testing device combined with a DL 2000 universal testing machine (EMIC, São José dos Pinhais, Paraná, Brazil). Loading was performed at a speed of $0.5 \mathrm{~mm} / \mathrm{min}$ until the specimens fractured.

To evaluate the interface and appearance of resin tags, one specimen was created for each self-etching adhesive system used $(n=1)$. The vestibular surface of each tooth was worn down in an abrasive (DP-10 Panambra, Ballerup, Denmark) using 320-grit silicon paper polishing to expose the facial surface, grind the dentin flat, and standardize the smear layer. The teeth were then submersed in an ultrasonic tub to remove excess debris and were subsequently washed with deionized water. Each tooth was restored using a different type of self-etching adhesive system: Clearfil SE Bond (Kuraray), AdheSE ${ }^{\circledR}$ (Ivoclar/Vivadent), Adper ${ }^{\mathrm{TM}}$ Easy One (3M $\left.{ }^{\mathrm{TM}} \mathrm{ESPE}^{\mathrm{TM}}\right)$, or OptiBond ${ }^{\mathrm{TM}}$ All-In-One ${ }^{\mathrm{TM}}$ (Kerr).

The teeth were longitudinally sectioned in a buccolingual plane. Each section was polished using 1200-grit silicon carbide abrasive paper. The specimens were cleaned ultrasonically in deionized water to remove the debris resulting from the abrasion. Each polished surface was then exposed to $6 \mathrm{~N}$ of $\mathrm{HCl}$ for $30 \mathrm{~s}$ and washed with deionized water. $\mathrm{Next}, 2.5 \% \mathrm{NaOCl}$ was applied for 10 minutes, and the specimens were then washed and dried using a light airblast. Impressions were made with addition silicone (Express ${ }^{\mathrm{TM}}$ XT Light Body, 3M ${ }^{\mathrm{TM}} \mathrm{ESPE}^{\mathrm{TM}}$, Brazil), and replicas were obtained using epoxy resin (Epofix, Stuers, Rodovre, Denmark). Next, the replicas were mounted on aluminum stubs and then coated with gold. The specimens were examined using SEM (JSM $66101 v ;$ JEOL) at a variety of magnifications. ${ }^{18}$

\section{RESULTS}

The mean microshear bond strength values and the respective standard deviation in each group are listed in Table 2. Two-way ANOVA and Tukey's test $(\mathrm{p}<0.05)$ were used in the statistical analysis. The two-way ANOVA test revealed that the interaction factor was not considered significant $(p=0.0527)$, nor was the effect of the dentin factor ( $p=0.1046)$. However, the effect of the adhesive factor was considered significant $(p=0.0002)$.

The highest overall average obtained for group $\mathrm{N}$ was when the OptiBond All-in-One adhesive was used. This value was followed by the values for Adper Easy One, Clearfil SE Bond, and AdheSE; there were no significant differences between them. The highest overall average obtained for group $\mathrm{H}$ was when the Adper Easy One adhesive was used. This value was followed by the values for OptiBond All-In-One, Clearfil SE Bond, and AdheSE; there were no significant differences between any of the values. With the exception of OptiBond, all of the means were found to be higher in group $\mathrm{H}$ than in group $\mathrm{N}$; however, no significant differences were found $(p<0.05)$.

The Clearfil SE Bond, AdheSE, Adper Easy One, and OptiBond All-In-One adhesive interfaces in groups $\mathrm{N}$ and $\mathrm{H}$ are shown in Figure 2.

Figure 2 also shows the small resin tags $(\mathrm{T})$ spread throughout the dentin substrate in group $\mathrm{N}(\mathrm{a}, \mathrm{b}, \mathrm{c}, \mathrm{d})$. No resin tags $(\mathrm{T})$ were found when the AdheSE self-etching adhesive system was used; only a hybrid layer $(\mathrm{H})$ was observed. Few tags (T) were observed in the case of Adper Easy One. Small resin tags were evident when OptiBond All-In-One was used.

The adhesive interfaces in group $\mathrm{H}(\mathrm{e}, \mathrm{f}, \mathrm{g}, \mathrm{h})$ are shown in Figure 2. In the case of Clearfil, small resin tags (T) were found, as were dentinal tubules (C) with salt deposits, which are also visible in the figure. A hybrid

Table 2: Mean \pm SD of microshear bond strength values (in MPa) of the adhesive systems applied on dentin with different degrees of mineralization as determined using two-way ANOVA and Tukey's test $(p<0.05)$

\begin{tabular}{lllll}
\hline Dentin & Clearfil SE Bond & AdheSE $^{\circledR}$ & Adper $^{\mathrm{TM}}$ Easy One & OptiBond $^{\mathrm{TM}}$ All-In-One $^{\mathrm{TM}}$ \\
\hline Normal & 15.65 Ab \pm 6.18 & $14.71 \mathrm{Ab} \pm 10.36$ & $21.92 \mathrm{Aab} \pm 6.40$ & $28.43 \mathrm{Aa} \pm 6.55$ \\
Hypermineralized & 20.96 Aab \pm 8.06 & 17.23 Ab \pm 5.16 & $31.79 \mathrm{Aa} \pm 8.31$ & $23.29 \mathrm{Aab} \pm 3.66$ \\
\hline
\end{tabular}




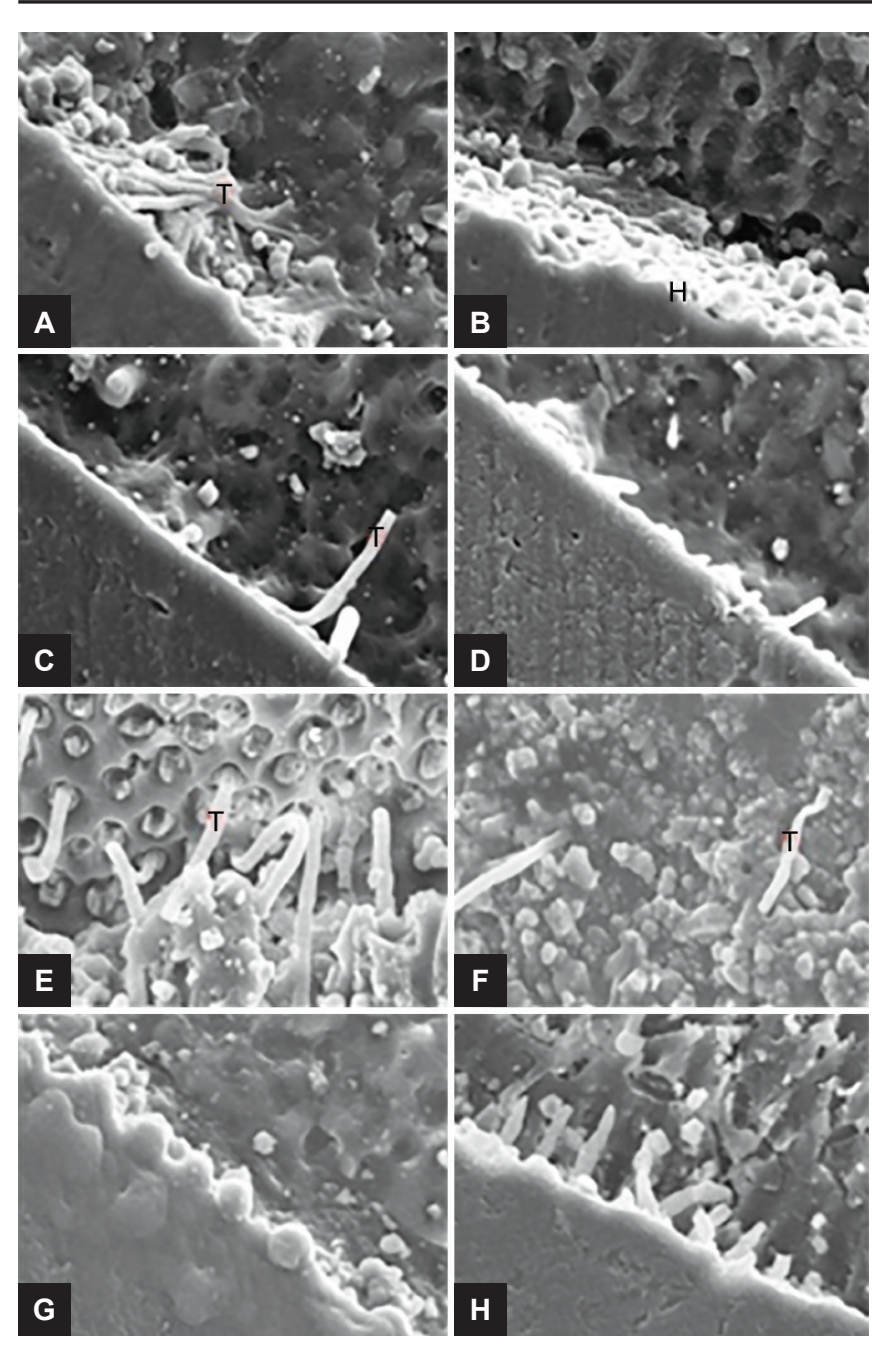

Figs 2A to $\mathrm{H}$ : Adhesive interface of the (A) Clearfil SE Bond, (B) AdheSE $^{\circledR},(C)$ Adper $^{\mathrm{TM}}$ Easy One, (D) OptiBond ${ }^{\mathrm{TM}}$ All-In-One ${ }^{\mathrm{TM}}$ systems used on normal dentin and the adhesive interface of the (E) Clearfil SE Bond, (F) AdheSE, (G) Adper Easy One; and (H) OptiBond All-In-One systems used on artificially hypermineralized dentin. T: Resin tags; H: Hybrid layer

layer was not found when the AdheSE self-etching adhesive system was used; only a few resin tags ( $\mathrm{T}$ ) were observed. In the case of Adper Easy One, no tags were found in the hybrid layer. Small resin tags were evident when OptiBond All-In-One was used.

\section{DISCUSSION}

The results show that microshear bond strength was dependent on the adhesion factor $(p=0.002)$, but the results involving dentin and interaction as factors were not statistically significant $(\mathrm{p}=0.1046$ and $\mathrm{p}=0.0527$ respectively). When bond strength is not considered under ideal conditions, it may be affected by factors, such as dentin type (normal vs artificially hypermineralized), the adhesive system used (etch-and-rinse vs self-etching), moisture, contaminants, the restorative material used, preparation time, desensitizing agents, and astringents.
Self-etching adhesive systems are being used with growing frequency due to the ease of the technique relative to etch-and-rinse adhesives. In general, two-step self-etching systems perform better than single-step systems. ${ }^{12,14}$ Restorations performed using self-etching adhesive systems initially exhibited limited durability, ${ }^{19}$ but as their formulations were improved, they came to exhibit excellent clinical performance for as long as 8 years. $^{20,21}$

Features of the dentin and the smear layer may affect the performance of self-etching adhesive. ${ }^{2}$ Some studies have found lower bond strength values for hypermineralized dentin compared with normal dentin, $7,13,22$ while others have reported no statistically significant differences between substrate types. ${ }^{6,23}$ Tay and Pashley ${ }^{22}$ analyzed hypermineralized dentin under SEM and found tubular obliteration, as well as acid-resistant hypermineralized layers, both of which hindered proper hybridization. It is believed that sclerotic dentin may restrict etching acids and in doing so, may negatively affect demineralization and the proper formation of tags. ${ }^{5,7}$ The adhesive interface analysis revealed more resin tags when Clearfil and OptiBond were used (20.96 and 23.29 MPa respectively). However, the presence of tags has little or no influence on bond strength, ${ }^{24,25}$ which may justify the finding of the highest bond strength in group $\mathrm{H}$ when Easy One adhesive was used (31.79 MPa), in which no tags were found.

Skupien et $\mathrm{al}^{9}$ found that self-etching adhesive systems with higher acidity levels have a greater effect on the micromorphology of the hybrid layer that forms; AdheSE was one of the adhesives used in their study. The higher the acidity of the self-etching adhesive systems, the more complex is the hybrid layer. ${ }^{18,26}$ The figure of the interface and the lower bond strength results obtained with the use of the AdheSE adhesive system (moderate level of acidity) are consistent with this assertion.

In group $\mathrm{N}$, the overall means obtained in the microshear test were found to be higher when the OptiBond All-In-One adhesive was used, followed by Adper Easy One, Clearfil SE Bond, and AdheSE. In group $\mathrm{H}$, the highest overall average was obtained when the Adper Easy One adhesive was used, followed by the values for OptiBond All-In-One, Clearfil SE Bond, and AdheSE. Some studies in the literature report that the composition and quality of the material used in the adhesive may be determining factors for clinical success. ${ }^{27}$ The composition of the self-etching adhesive systems used herein can be found in Table 1.

The hydrophilic monomer 2-hydroxyethyl methacrylate, which is responsible for enabling the product to enter the dentin ${ }^{28}$ is present in all of the adhesive systems used herein, with the exception of OptiBond All-In-One. The 
absence of this monomer may have limited the adhesive's ability to penetrate the hypermineralized dentin, which would explain the lower resistance to microshear on this surface only in the case of the OptiBond adhesive.

The solvent is an essential component for obtaining dentin adhesion, because, when combined with hydrophilic monomers, the solvent drastically improves adhesion performance. ${ }^{21}$ The presence of water, acetone, and ethanol as solvents in the OptiBond All-In-One adhesive may explain the higher mean obtained on the microshear test in group $\mathrm{N}$ relative to the other adhesives, which contained only water as a solvent.

It is known that bovine teeth may be used as substitutes for human teeth in studies considering bond strength, ${ }^{16}$ though they are not considered a perfect replacement. ${ }^{1}$ The advantage of using bovine teeth is greater standardization of the substrate, which produces more reliable results. Human teeth vary substantially in structure and dentin compositions and are often recently erupted teeth, which, therefore, exhibit high permeability. Bovine teeth were chosen for this study to avoid this variability.

Shear bond strength was originally the most commonly used tool for assessing bond strength. One of the most important problems in shear testing is the relatively common occurrence of cohesive failures. The cohesive failures found in microshear bond tests may develop as a result of undesired stress produced by the method itself. Microshear bond strength enables the analysis of small bonded areas in a single tooth while generating very little stress. In this case, the failures may occur largely on the adhesive interface, and the adhesive area delimitation for the microshear bond test may be used to prevent fractures from occurring beyond the adhesive area. ${ }^{17,29}$ Microshear bond strength with adhesive delimitation was, therefore, selected for the current study.

\section{CONCLUSION}

Within the limitations and based on the results obtained in this study, it can be affirmed that single-step selfetching adhesive systems exhibit higher immediate bond strength values in cases of both normal and hypermineralized dentin. All of the self-etching systems used in this study produced acceptable bond strength for both normal and hypermineralized substrates. These two dentin types were not found to affect the results of microshear bond testing.

The micromorphology of the adhesive interface varies depending on the type of self-etching adhesive used and may exhibit hybrid layers of different thicknesses or even small resin tags.

It can be stated that clinical success is fundamental for dentistry practice. For this reason, studies are performed to aid in the development of adhesive systems that provide ease of technique, cosmetic and functional excellence, effective adhesion, and optimal short-term and long-term performance. It is important to obtain bond strength values to analyze the possible clinical performance of these adhesive systems. Furthermore, information on their interactions with different types of dentin substrates proved complementary and useful in the study performed herein.

\section{REFERENCES}

1. Sato K, Hosaka K, Takahashi M, Ikeda M, Tian F, Komada W, Nakajima M, Foxton R, Nishitani Y, Pashley DH, et al. Dentin bonding durability of two-step self-etch adhesives with improved of degree of conversion of adhesive resins. J Adhes Dent 2017 Feb;19(1):31-37.

2. BouillaguetS, Gysi P, Wataha JC, Ciucchi B, Cattani M, Godin C, Meyer JM. Bond strength of composite to dentin using conventional, one-step, and self-etching adhesive systems. J Dent 2001 Jan;29(1):55-61.

3. Yoshiyama M, Sano H, Ebisu S, Tagami J, Ciucchi B, Carvalho RM, Johnson MH, Pashley DH. Regional strengths of bonding agents to cervical sclerotic root dentin. J Dent Res 1996 Jun;75(6):1404-1413.

4. Karakaya S, Unlu N, Say EC, Ozer F, Soyman M, Tagami J. Bond strengths of three different dentin adhesive systems to sclerotic dentin. Dent Mater J 2008 May;27(3):471-479.

5. Kwong SM, Tay FR, Yip HK, Kei LH, Pashley DH. An ultrastructural study of the application of dentine adhesives to acidconditioned sclerotic dentine. J Dent 2000 Sep;28(7):515-528.

6. van Dijken JW. A prospective 8-year evaluation of a mild two-step self-etching adhesive and a heavily filled two-step etch-and-rinse system in non-carious cervical lesions. Dent Mater 2010 Sep;26(9):940-946.

7. Van Meerbeek B, Braem M, Lambrechts P, Vanherle G. Morphological characterization of the interface between resin and sclerotic dentine. J Dent 1994 Jun;22(3):141-146.

8. Dieng-Sarr F, Sharrock P, Dabsie F, Grégoire G. Modifications of the organic and mineral fractions of dental tissues following conditioning by self-etching adhesives. J Dent 2011 Feb;39(2):141-147.

9. Skupien JA, Susin AH, Angst PD, Anesi R, Machado P, Bortolotto T, Krejci I. Micromorphological effects and the thickness of the hybrid layer-a comparison of current adhesive systems. J Adhes Dent 2010 Dec;12(6):435-442.

10. Bowen RL. Adhesive bonding of various materials to hard tooth tissues. II. Bonding to dentin promoted by a surfaceactive comonomer. J Dent Res 1965 Sep-Oct;44(5):895-902.

11. Santos MJM, Costa MD, Rêgo HM, Rubo JH, Santos GC Jr. Effect of surface treatments on the bond strength of selfetching adhesive agents to dentin. Gen Dent 2017Jul-Aug; 65(4):e1-e6.

12. Cilli R, Prakki A, de Araújo PA. Evaluating a method of artificially hypermineralizing dentin to simulate natural conditions in bonding studies. J Adhes Dent 2005 Winter;7(4): 271-279.

13. Perdigao J, Swift EJ Jr, Denehy GE, Wefel JS, Donly KJ. In vitro bond strengths and SEM evaluation of dentin bonding systems to different dentin substrates. J Dent Res 1994 Jan;73(1):44-55. 
14. Ito S, Hoshino T, Iijima M, Tsukamoto N, Pashley DH, Saito T. Water sorption/solubility of self-etching dentin bonding agents. Dent Mater 2010 Jul;26(7):617-626.

15. Joynt RB, Davis EL, Wieczkowski G Jr, Yu XY. Dentin bonding agents and the smear layer. Oper Dent 1991 Sep-Oct;16(5): 186-191.

16. Nakabayashi, N.; Pashley, DH. Hybridization of dental hard tissues. Georgia: Quintessence; 1998.

17. Shimaoka AM, de Andrade AP, Cardoso MV, de Carvalho RC. The importance of adhesive area delimitation in a microshear bond strength experimental design. J Adhes Dent 2011 Aug;13(4):307-314.

18. Wang Y, Spencer P. Physiochemical interactions at the interfaces between self-etch adhesive systems and dentine. J Dent 2004 Sep;32(7):567-579.

19. Watanabe I, Nakabayashi N. Bonding durability of photocured phenyl-P in TEGDMA to smear layer-retained bovine dentin. Quintessence Int 1993 May;24(5):335-342.

20. Burrow MF, Tyas MJ. Comparison of two all-in-one adhesives bonded to non-carious cervical lesions-results at 3 years. Clin Oral Investig 2012 Aug;16(4):1089-1094.

21. Tay FR, Pashley DH. Have dentin adhesives become too hydrophilic? J Can Dent Assoc 2003 Dec;69(11):726-731.

22. Tsai YL, Nakajima M, Wang CY, Foxton RM, Lin CP, Tagami J. Influence of etching ability of one-step self-etch adhesives on bonding to sound and non-carious cervical sclerotic dentin. Dent Mater J 2011 Nov;30(6):941-947.

23. Tuncer D, Yazici AR, Özgünaltay G, Dayangac B. Clinical evaluation of different adhesives used in the restoration of non-carious cervical lesions: 24-month results. Aust Dent J 2013 Mar;58(1):94-100.

24. Tay FR, Pashley DH. Resin bonding to cervical sclerotic dentin: a review. J Dent 2004 Mar;32(3):173-196.

25. Wang R, Shi Y, Li T, Pan Y, Cui Y, Xia W. Adhesive interfacial characteristics and the related bonding performance of four self-etching adhesives with different functional monomers applied to dentin. J Dent 2017 Jul;62:72-80.

26. He Z, Chen L, Shimada Y, Tagami J, Ruan S. Evaluation of subsurface penetration and bonding durability of self-etching primer systems to Er:YAG laser treated cervical dentin. Dent Mater J 2017 Mar;36(2):174-181.

27. Perdigão J. New developments in dental adhesion. Dent Clin North Am 2007 Apr;51(2):333-357.

28. Perdigão J, Van Meerbeek B, Lopes MM, Ambrose WW. The effect of a re-wetting agent on dentin bonding. Dent Mater 1999 Jul;15(4):282-295.

29. Andrade AM, Garcia E, Moura SK, Reis A, Loguercio A, Silva LM, Pimentel GH, Grande RH. Do microshear test variables affect the bond strength values? Int J Dent 2012 Oct;2012:1-6. 